\title{
Vulnerability of Zostera marina seedlings to physical stress
}

\author{
T. Valdemarsen*, P. Canal-Vergés, E. Kristensen, M. Holmer, M. D. Kristiansen, \\ M. R. Flindt
}

Institute of Biology, University of Southern Denmark, Campusvej 55, 5230 Odense M, Denmark

\begin{abstract}
Eelgrass coverage in Odense Fjord (Denmark) has declined by $90 \%$ since 1983, due to eutrophication and its associated pressures, and the state of low eelgrass coverage has remained stable despite 10 to 15 yr of reduced nutrient loading and improved water quality. We hypothesize that the survival of eelgrass seedlings, and thus recolonization through reproductive dispersal, is negatively affected by physical disturbances. The 3 most likely physical mechanisms involved are uprooting or burial through drifting macroalgae, Arenicola marina sediment reworking and current-driven sediment resuspension. Our hypothesis was tested by field observations during the summer of 2009, when the mortality of seedlings was followed through time. The density of seedlings decreased dramatically by $80 \%$ during the first month of observations, and no seedlings survived past August, corresponding to an average seedling mortality of $1.5 \% \mathrm{~d}^{-1}$. This was $>3$ times higher than the mortality for seedlings protected from physical disturbance by enclosures $\left(0.4 \% \mathrm{~d}^{-1}\right)$, indicating that physical disturbance contributed to high seedling mortality. A significant correlation $(p=0.02)$ between macroalgal drift and seedling mortality suggested that $\sim 40 \%$ of seedlings were lost due to the physical disturbance of drifting algae. In contrast, no correlations were found between $A$. marina reworking or resuspension and seedling mortality, despite a mobility of up to $400 \mathrm{~cm}^{3}$ sediment $\mathrm{m}^{-2} \mathrm{~d}^{-1}$ by these mechanisms. Given the observed intensity of macroalgal drift, we speculate that this mechanism severely hampers eelgrass reestablishment in certain parts of Odense Fjord.
\end{abstract}

KEY WORDS: Eelgrass · Macroalgal drift · Bedload transport · Fucus sp. · Sediment · Reworking · Resuspension · Arenicola marina

Resale or republication not permitted without written consent of the publisher

\section{INTRODUCTION}

Eelgrass Zostera marina L., the most common seagrass in the northern hemisphere, has declined along European and North American coasts during the last century. Eelgrass was first hit hard by wasting disease during the 1930s (e.g. Petersen 1934) and later by anthropogenically driven eutrophication that led to hypoxic events, reduced light climate, stimulated epiphyte growth and increased competition from macroalgae (Hauxwell et al. 2003, Greve et al. 2005). Human activities in coastal areas (e.g. construction and dredging) also threaten seagrass ecosystems worldwide (Cabaco et al. 2008). In recent years substantial efforts have been devoted to reducing anthropogenic pres- sure and facilitating seagrass recovery (e.g. Greening \& Janicki 2006, Petersen et al. 2009, Marion \& Orth 2010, van Katwijk et al. 2010). However, natural recolonization has been less successful than predicted or has occurred, often for unknown reasons, slowly despite marked improvements in water quality (e.g. Frederiksen et al. 2004, Greening \& Janicki 2006, van der Heide et al. 2007). Thus, a more detailed understanding of the key processes affecting the recovery of seagrasses is urgently needed.

Vegetative expansion of Zostera marina meadows by clonal growth is efficient for recovery of gaps (up to $100 \mathrm{~m}^{-2}$ ) in the seagrass landscape (Bell et al. 1999, Olesen et al. 2004), but is insufficient for large-scale recolonization, due to slow ( 0.3 to $\left.0.5 \mathrm{~m} \mathrm{yr}^{-1}\right)$ rhizome 
elongation (Olesen \& Sand-Jensen 1994, Townsend \& Fonseca 1998, Boese et al. 2009). Recolonization of larger areas, therefore, depends primarily on seed dispersal and the subsequent growth of seedlings (Olesen \& Sand-Jensen 1994, Plus et al. 2003, Greve et al. 2005, Jarvis \& Moore 2010). Z. marina has a high capacity for sexual reproduction, whereby seeds are released during late summer and fall, resulting in densities of from $10^{2}$ to $10^{4}$ seeds $\mathrm{m}^{-2}$ inside eelgrass beds and up to $30-50$ seeds $\mathrm{m}^{-2}$ at a distance of $15 \mathrm{~m}$ from established beds (Harrison 1993, Olesen \& Sand-Jensen 1994, Orth et al. 1994, Olesen 1999, Probert \& Brenchley 1999, Boese \& Robbins 2008). However, only 5 to $15 \%$ of seeds germinate to produce seedlings the following spring (Harrison 1993, Orth et al. 2003), resulting in low seedling density $\left(0.2\right.$ to $\left.26 \mathrm{~m}^{-2}\right)$ outside established beds (Olesen \& Sand-Jensen 1994, Greve et al. 2005, Boese \& Robbins 2008). Hence, net expansion of eelgrass coverage depends primarily on the survival of a low number of seedlings to form new patches and eventually to create a continuous seagrass landscape through vegetative growth (Olesen \& SandJensen 1994, Almela et al. 2008).

Seedling survival varies between habitats from $>80 \% \mathrm{yr}^{-1}$, with complete recolonization in some areas (Plus et al. 2003, Lee et al. 2007), to between 0 and $5 \%$ $\mathrm{yr}^{-1}$ and much slower recolonization in most areas (Churchill 1983, Harrison 1993, Greve et al. 2005, Bos \& van Katwijk 2007, Boese et al. 2009). A low percentage of seedling survival ( 0 to $5 \%$ ) is also reported from large-scale Zostera marina restoration projects with seeds (Marion \& Orth 2010). The general low seedling survival is explained by environmental factors, but only few studies have yet provided direct evidence of the stress factors governing seedling mortality. Hydrodynamic forcing has been suggested to be critical during seedling establishment (Olesen \& Sand-Jensen 1994, Fonseca \& Bell 1998, Bos \& van Katwijk 2007); for instance, Olesen \& Sand-Jensen (1994) observed a high mortality of seedlings and of seagrass patches younger than 2 yr old due to a lack of self protection against water currents. Similarly, Boese \& Robbins (2008) identified macroalgal drift to be a critical process in the loss of shoots and seedlings. Furthermore, undermining and burial due to sediment resuspension (Mills \& Fonseca 2003, Cabaco \& Santos 2007), burial and physical damage by bioturbating fauna (Philippart et al. 1994, Davis et al. 1998, Dumbauld \& WyllieEcheverria 2003) and increased light attenuation, hypoxia and accumulation of toxic compounds (Hauxwell et al. 2001, Cummins et al. 2004, Boese \& Robbins 2008) may also be important processes, but have only been evaluated for adult seagrasses. Thus, in any given environment, multiple stressors probably govern seedling mortality, and knowledge of their rel- ative impact is critical to understand the variations in seagrass recolonization in coastal habitats.

Odense Fjord is a shallow estuary, located in the northeastern area of the island of Fyn, Denmark (Fig. 1). In 1983, a fjord-wide survey of submerged macrophytes showed that $\sim 15 \mathrm{~km}^{2}$ of the outer fjord was covered with Zostera marina. Since then $\sim 90 \%$ of the Z. marina has been lost (Fyns Amt 2006), probably due to excessive nutrient loading from the watershed and the associated reduced light levels, competition from opportunistic macroalgae (e.g. Ulva lactuca and Chaetomorpha sp.) (e.g. Hauxwell et al. 2001) and hypoxic events (e.g. Greve et al. 2005) that characterized the 1990s. However, the nutrient loading has gradually been reduced (especially for P) since 1990 and water quality has improved, as evidenced by higher water transparency and the recession of opportunistic macroalgae (Fyns Amt 2006, Petersen et al. 2009). Furthermore, hypoxic conditions were last reported in October 2000 (monitored monthly from July to November from 1997 to the present by the Danish National Environmental Research Institute). Despite these improvements, no recovery of $Z$. marina has occurred.

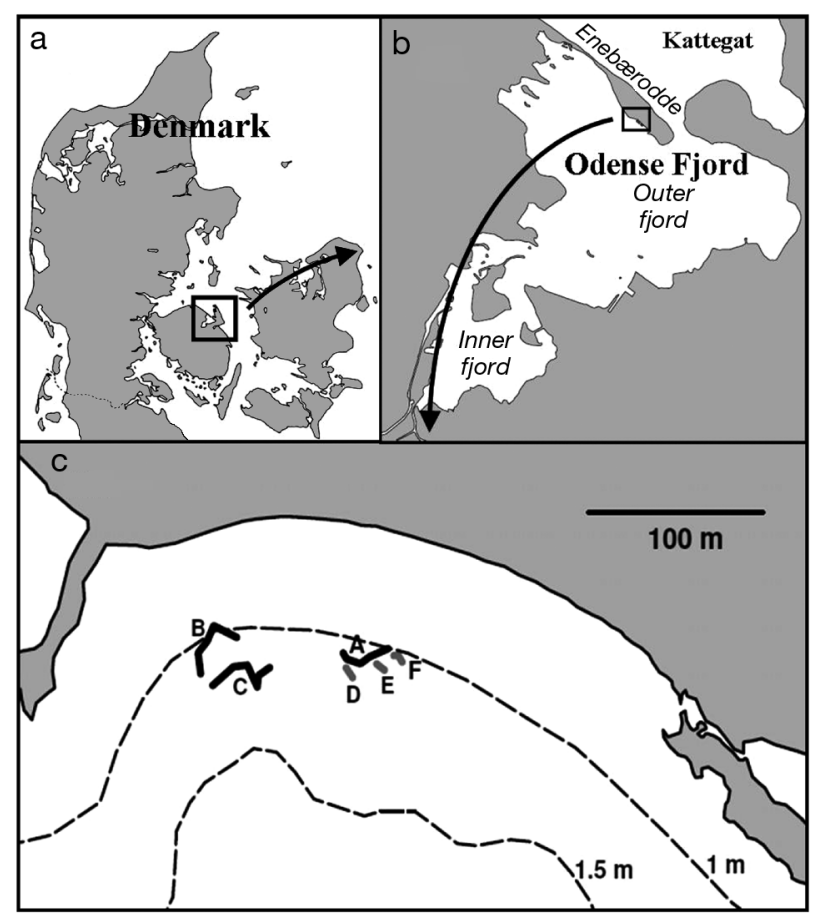

Fig. 1. Location of (a) Denmark, (b) inner and outer Odense Fjord, Kattegat and Enebærodde and (c) detailed overview of the study area. A, B and C in (c) indicate transects where Zostera marina seedlings were not protected, whereas D, E and $F$ indicate transects where individual seedlings were protected from physical stress by transparent enclosures. Grey and white indicate land and water, respectively. In (c), dashed lines indicate water depth 
The present study was conducted at a site where a 0.4 ha shallow eelgrass population remains. The surrounding area was previously populated by Zostera marina (Fyns Amt 2006), but is now bare sediment with scattered and drifting patches of the brown algae Fucus vesiculosus. The studied $Z$. marina population produces seedlings every year, and there are no apparent environmental differences between vegetated and unvegetated sediment. Therefore, it was hypothesized that physical disturbance prevents the spread of $Z$. marina into the adjacent unvegetated areas. This hypothesis was tested by quantifying seedling performance and the potential processes affecting seedling mortality in the unvegetated areas near the fringes of $Z$. marina beds. The most dominant physical processes (macroalgal drift, Arenicola marina sediment reworking and current-driven resuspension) were quantified, and their relative importance for seedling mortality was evaluated.

\section{MATERIALS AND METHODS}

Odense Fjord. The Odense Fjord estuary $(2.2 \mathrm{~m}$ average water depth at mean sea level and $0.3 \mathrm{~m}$ tidal amplitude, respectively) covers $62 \mathrm{~km}^{2}$ and is divided into an inner and an outer part (Fig. 1). The shallow inner fjord (0.8 $\mathrm{m}$ average depth) comprises one-fourth of the total area and is impacted by freshwater inputs from the Odense River. The outer fjord has a more variable bathymetry (2.7 $\mathrm{m}$ average depth) and opens to the Kattegat through a narrow opening in the northeast (Fig. 1). Salinity varies depending on freshwater input and exchange with the Kattegat from 5 to 17 and 15 to 25 in the inner and outer fjord, respectively (Fyns Amt 2006), with the lowest salinity typically measured during winter. Odense Fjord has a large catchment area $\left(1046 \mathrm{~km}^{2}\right)$, resulting in substantial nutrient loading primarily due to agricultural runoff. Nutrient loading was $2500 \mathrm{t} \mathrm{N} \mathrm{yr}^{-1}$ and $300 \mathrm{t} \mathrm{P} \mathrm{yr}^{-1}$ prior to 1990, but after the implementation of several water action plans nutrient loading was gradually reduced to the present levels (2000 t N yr-1 and $50 \mathrm{t} \mathrm{P} \mathrm{y}^{-1}$ ) (Petersen et al. 2009).

Study site. The present study was conducted at a narrow tongue of land ('Enebærodde') that stretches into the outer part of Odense Fjord (Fig. 1), where Zostera marina is found in a $\sim 100 \times 400 \mathrm{~m}$ area at 0.5 to $1.5 \mathrm{~m}$ depth. At this site the $Z$. marina landscape has a patchy appearance consistent with moderate hydrodynamic forcing (Fonseca \& Bell 1998, Bell et al. 1999), where patches ranging from a few to $>100 \mathrm{~m}^{2}$ are intertwined with narrow channels $(0.5$ to $3 \mathrm{~m})$ of bare sediment. Apart from a few populations located in deeper water ( 2 to $3 \mathrm{~m}$ depth), the conditions at the study site resemble those at most of the remaining $Z$. marina populations in Odense Fjord with respect to water depth.

Sediment characteristics of vegetated and bare sediment. Sediment characteristics were determined inside 3 randomly chosen Zostera marina patches and on bare sediment $1 \mathrm{~m}$ adjacent to every patch. For each patch, 3 sediment cores (8 $\mathrm{cm}$ in diameter, i.d.) were sampled from vegetated and bare sediment. Sediment characteristics were determined on subsamples from 0 to 1,1 to 2,2 to 6 and 6 to $15 \mathrm{~cm}$ depth intervals for every core. Wet density was determined as weight of a known volume of sediment using cut-off syringes; water content was determined as weight loss (\%) of wet sediment after drying $\left(24 \mathrm{~h}, 105^{\circ} \mathrm{C}\right)$, and organic content (\%) was determined as weight loss of dry sediment after ignition (LOI, $5 \mathrm{~h}, 520^{\circ} \mathrm{C}$ ). Furthermore, for every examined patch, grain size distribution was determined on one vegetated and one bare sediment core, by wet sieving a sediment subsample through a Wentworth series of meshes. Median grain size was determined from the $\Phi$-distribution of size fractions (Krumbein 1936).

Quantification of seedling loss. Since seedling density was low (average $<1 \mathrm{~m}^{-2}$ ) and patchily distributed in early June 2009, when the present study was initiated, quantification of seedlings by density according to area counts (e.g. Boese et al. 2009) was inappropriate. Seedling performance was instead quantified from the fate of individual seedlings by marking their exact positions ( $\pm 10 \mathrm{~cm}$ precision) along permanent transect cords. This approach did not yield absolute changes of seedling density, but provided evidence of the temporal changes of monitored seedlings. The permanent transects were established below the intertidal zone at 1 to $1.2 \mathrm{~m}$ water depth (Fig. 1). The transects were established on bare sediment in the channels between existing Zostera marina beds; this resulted in the twisted appearance of transects as seen in Fig. 1. Transects were tracked with $40 \mathrm{~m}$ weighted cord (1.2 cm i.d., $430 \mathrm{~g} \mathrm{~m}^{-1}$ ) firmly anchored in the sediment, with $0.3 \mathrm{~m}$ long plugs every 1 to $2 \mathrm{~m}$. The position of individual $Z$. marina seedlings was marked by attaching identification tags to the transect cord. Seedlings were always located $\sim 40 \mathrm{~cm}$ away from the transect cord to exclude the effects of cord, markers and plugs. Only seedlings $>50 \mathrm{~cm}$ from established beds were considered to exclude vegetative shoots. A total of 23, 30 and 29 seedlings were marked on Transect A, B and $\mathrm{C}$, respectively.

To demonstrate the importance of physical disturbance for seedling survival, 3 additional transects (Transect D, E and F) were established in the same area (Fig. 1). Enclosures were placed over each seedling to exclude physical stress due to, e.g., water 
currents (van Katwijk \& Hermus 2000). Five seedlings were enclosed individually along each protected transect by $7.2 \mathrm{~cm}$ i.d., $40 \mathrm{~cm}$ long, transparent core liners that were gently pushed 10 to $15 \mathrm{~cm}$ into the sediment. Core liners were perforated with holes to insure that enclosed seedlings were subjected to the same water exchange and nutrient regime as the surroundings. The upper opening of core liners was sealed with transparent plastic film to prevent sediment accumulation inside the enclosures. Since the surface of enclosures acted as substratum for microalgal growth, they were cleaned regularly to prevent reduced light climate for enclosed seedlings.

Transects were inspected 1 or 2 times per week from mid-June until no seedlings remained in Transects A, B and $C$ (late August). All movement in the transect area occurred by snorkeling to keep disturbance due to moving personnel at a minimum. On each sampling occasion, transect cords and the area surrounding each individual seedling were cleared of drifting macroalgae (see 'Determination of physical stressors') and the remaining seedlings were quantified. Furthermore, the most probable cause for seedling loss was evaluated by visual inspection of the environment. Seedling density (\%) was reported relative to initial number of seedlings.

Determination of physical stressors. Macroalgal coverage on Transects $\mathrm{A}, \mathrm{B}$ and $\mathrm{C}$ was measured weekly as the cumulated coverage (\% of transect length) within $\pm 25 \mathrm{~cm}$ on each side of the transect line. Furthermore, every week, a representative sample of macroalgae (e.g. material recovered from $0.5 \times 1 \mathrm{~m}$ on each transect) was brought to the laboratory for determination of species composition and biomass (wet weight and dry weight after drying, $72 \mathrm{~h}, 60^{\circ} \mathrm{C}$ ). The average biomass $\left(\mathrm{g} \mathrm{m}^{-2}\right)$ of algal material along transects was extrapolated from the total coverage of macroalgae on transects and the biomass per unit in the sampled area of $0.5 \mathrm{~m}^{2}$. Since transects were cleaned from macroalgae every week, the average biomass of new algal material was equivalent to a measure of macroalgal drift between observations. The drift estimates probably captured only a fraction of the total algal material that was transported between observations, but they were assumed to be proportional to total macroalgal drift.

The physical characteristics of drifting Fucus sp. were characterized in a survey conducted between June 23 and 29. A subsample of drifting Fucus sp. with anchors $(n=37)$ was collected at the study site. Wet weight and dry weight of Fucus sp. biomass was determined by the methods described above. Furthermore, the wet weight of attached anchors was measured.

The density of Arenicola marina on Transects A, B and $\mathrm{C}$ was determined every week by counting the number of faecal casts within \pm 25 on each side of tran- sect lines. Average density $\left(\mathrm{m}^{-2}\right)$ was obtained by dividing the number of faecal casts by the area represented by transects. Furthermore, the in situ sediment reworking intensity was estimated every 1 to $2 \mathrm{wk}$ from early July to late August by digital image analysis. The sediment surface of five $0.5 \times 0.5 \mathrm{~m}$ quadrants away from the transects was smoothed to erase visible signs of sediment reworking. Newly deposited faecal casts produced after 1 to $2 \mathrm{~h}$ of incubation were photographed and later quantified by digital image analysis. Photographs were registered to known scale in GIS software (MapInfo), and the length and width of faecal casts was determined. The volume of faecal casts was calculated assuming a cylindrical shape for feces and normalized to incubation time to yield sediment reworking intensity $\left(\mathrm{cm}^{3}\right.$ sediment $\left.\mathrm{m}^{-2} \mathrm{~d}^{-1}\right)$.

Sediment resuspension was measured by sediment traps ( $\mathrm{n}=4$ ) that consisted of core liners (5 cm i.d., $35 \mathrm{~cm}$ length) closed in the bottom end with rubber stoppers and mounted to $1 \mathrm{~m}$ steel pipes. The trap opening was placed $\sim 40 \mathrm{~cm}$ above the sediment surface, and traps were collected every 1 to 2 wk during the study period. Dry weight of total accumulated matter (TM) was determined as weight after drying $(24 \mathrm{~h}$, $105^{\circ} \mathrm{C}$ ), and organic content of deposited material was determined as weight loss after combustion $(5 \mathrm{~h}$, $520^{\circ} \mathrm{C}$ ). Average TM deposition (g dry wt $\mathrm{m}^{-2} \mathrm{~d}^{-1}$ ) was calculated as TM accumulation between observations normalized to incubation time.

Statistical procedures. Differences between vegetated and bare sediment (wet density, water content, LOI, median grain size and silt-clay percentage) were detected by pairwise $t$-tests for individual depth layers. A Mann-Whitney test was used when data were not normally distributed. The importance of macroalgal drift, Arenicola marina sediment reworking and sediment resuspension for rates of seedling loss was evaluated by Pearson correlation analysis. Tests for normality, $t$-tests and correlation analysis were performed with SigmaStAT at a significance level of $\alpha=0.05$.

\section{RESULTS}

\section{Sediment characteristics}

Bare sediment at Enebærodde consisted of organically poor (0.5 to $0.9 \%$ LOI), well-sorted fine sand, with a medium grain size of $\sim 180 \mu \mathrm{m}$ and a silt-clay percentage of $<1.6 \%$ (Table 1). Average density and water content were $1.85 \pm 0.04 \mathrm{~g} \mathrm{~cm}^{-3}$ and $21.1 \pm 1.92 \%$, respectively. There were no significant differences between bare and vegetated sediment, except for marginally lower density and slightly higher LOI in the upper $6 \mathrm{~cm}$ of the vegetated sediment (Table 1). 
Table 1. Sediment characteristics to $15 \mathrm{~cm}$ depth for vegetated and bare sediment at Enebærodde. All parameters are presented as averages $( \pm S D, n=9$ for density, water content and loss on ignition, LOI; $\mathrm{n}=3$ for median grain size and silt-clay fraction). ${ }^{*}$ Significant differences $(p<0.05)$ between sediment types

\begin{tabular}{|llllll|}
\hline & $\begin{array}{c}\text { Density } \\
\left(\mathrm{g} \mathrm{cm}^{-3}\right)\end{array}$ & $\begin{array}{c}\text { Water } \\
\text { content } \\
(\% \text { wet wt })\end{array}$ & $\begin{array}{c}\text { LOI } \\
(\% \text { dry wt })\end{array}$ & $\begin{array}{c}\text { Median } \\
\text { grain } \\
\text { size }(\mu \mathrm{m})\end{array}$ & $\begin{array}{c}\text { Silt-clay } \\
\text { fraction } \\
(\% \text { dry wt })\end{array}$ \\
\hline Vegetated sediment & & & & \\
$0-1 \mathrm{~cm}$ & $1.85 \pm 0.03^{*}$ & $24.3 \pm 1.2^{*}$ & $0.88 \pm 0.15^{*}$ & $171 \pm 11$ & $1.59 \pm 0.40$ \\
$1-2 \mathrm{~cm}$ & $1.82 \pm 0.04^{*}$ & $21.6 \pm 0.9^{*}$ & $0.68 \pm 0.10^{*}$ & $173 \pm 11$ & $0.95 \pm 0.60$ \\
$2-6 \mathrm{~cm}$ & $1.79 \pm 0.04$ & $21.0 \pm 1.1^{*}$ & $0.66 \pm 0.14^{*}$ & $172 \pm 3$ & $1.00 \pm 0.60$ \\
$6-15 \mathrm{~cm}$ & $1.81 \pm 0.05$ & $20.6 \pm 0.5$ & $0.58 \pm 0.09$ & $176 \pm 3$ & $1.07 \pm 0.50$ \\
& & & & & \\
Bare sediment & & & & \\
$0-1 \mathrm{~cm}$ & $1.90 \pm 0.02^{*}$ & $22.5 \pm 2.0^{*}$ & $0.70 \pm 0.14^{*}$ & $182 \pm 24$ & $1.35 \pm 0.82$ \\
$1-2 \mathrm{~cm}$ & $1.86 \pm 0.03^{*}$ & $20.0 \pm 1.0^{*}$ & $0.53 \pm 0.07^{*}$ & $182 \pm 25$ & $1.32 \pm 0.17$ \\
$2-6 \mathrm{~cm}$ & $1.81 \pm 0.03$ & $19.0 \pm 1.0^{*}$ & $0.46 \pm 0.02^{*}$ & $190 \pm 35$ & $0.95 \pm 0.02$ \\
$6-15 \mathrm{~cm}$ & $1.84 \pm 0.05$ & $19.8 \pm 1.1$ & $0.49 \pm 0.05$ & $190 \pm 11$ & $0.89 \pm 0.38$ \\
\hline
\end{tabular}

\section{Loss of seedlings}

Seedling density along Transects A, B and C decreased dramatically by $80 \%$ from mid-June to mid-July, with a loss rate of up to $5.2 \% \mathrm{~d}^{-1}$ (average: $3.1 \% \mathrm{~d}^{-1}$ ) (Fig. 2). Subsequently, seedling density decreased gradually and reached zero by the end of August. All seedlings initially appeared healthy, with bright green leaves and no epiphyte growth. The decline during the first month occurred abruptly, without any apparent tissue deterioration, as is common when shoots are stressed by poor growth conditions (e.g. Mascaro et al. 2009). Most seedlings disappeared without any trace between observations, while some remaining seedlings showed evidence of physical disturbance (e.g. cut off or damaged leaves and partially exposed roots and rhizomes).
Seedlings enclosed by transparent core liners showed much lower mortality than non-enclosed seedlings (on average $0.4 \% \mathrm{~d}^{-1}$ ), and 11 out of 15 seedlings still remained by the end of August (Fig. 2). Enclosed seedlings had dense epiphyte growth from the end of June, probably due to hampered water exchange within the core liners. Epiphyte growth did not, however, appear critical, since enclosed seedlings showed positive growth during the study period (e.g. leaf length increased 4 - to 6 -fold to $20-35 \mathrm{~cm}$ ). At least 2 enclosed seedlings were lost due to Arenicola marina intruding the core liners from below and subsequent burial by their reworking activities, and only 2 enclosed seedlings were lost to unknown factors.

\section{Drifting macroalgae}

The study area was strongly impacted by drifting macroalgae during the entire observation period. On June 23, Transects A, B and C had $22 \%$ cover of drifting material, which resulted in a net accumulation of $260 \pm 57 \mathrm{~g}$ wet wt $\mathrm{m}^{-2}$ (Fig. 3). From June 23 algal drift declined steadily to reach $3 \%$ coverage and $24 \mathrm{~g}$ wet wt $\mathrm{m}^{-2}$ on July 6 . From July 6 to 20 , algal drift was low $\left(3.4 \pm 1.2 \%\right.$ coverage and $27 \pm 8 \mathrm{~g}$ wet wt $\left.\mathrm{m}^{-2}\right)$, but from July 29 the importance of algal drift increased steadily to reach an average of $11 \pm 3 \%$ coverage and $105 \pm 22 \mathrm{~g}$ wet wt $\mathrm{m}^{-2}$ in August. Drifting material was composed primarily of Fucus vesci-
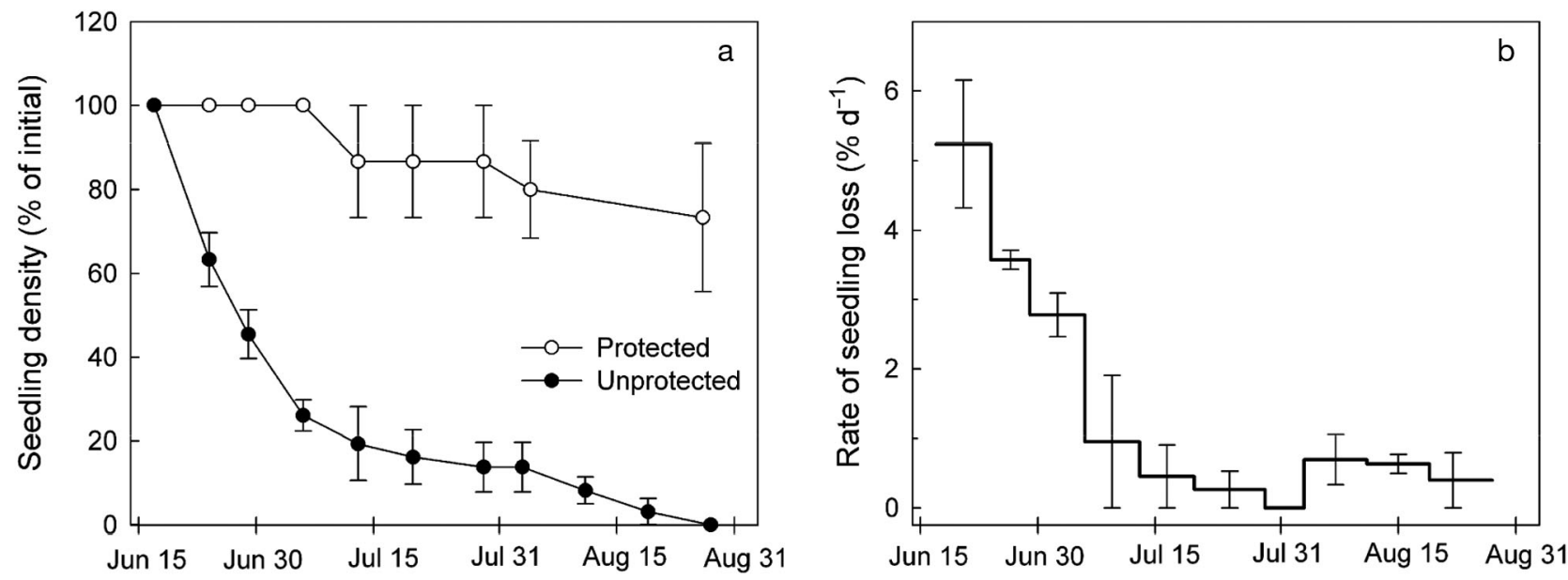

Fig. 2. (a) Density of Zostera marina seedlings as percent of initial seedling density on unprotected (•) and protected (O) transects and $(\mathrm{b})$ average rate of seedling loss $\left(\% \mathrm{~d}^{-1}, \mathrm{n}=3\right)$ on unprotected transects in 2009. Error bars indicate $\mathrm{SE}$ 
culosus, which constituted $>50 \%$ of total macroalgal biomass during the period of most rapid seedling loss (June 16 to July 13). The remainder was composed of varying amounts of filamentous algae (Ectocarpus sp., Chaetomorpha sp. and Gracillaria sp.) and Zostera marina debris (Fig. 3). On average, bulk drifting material had $74 \%$ water content. Approximately $50 \%$ by mass of recovered $F$. vesiculosus was still attached to their anchors (e.g. small stones or mussels), and the survey of drifting individuals $(\mathrm{n}=37)$ revealed an average $( \pm \mathrm{SE})$ wet biomass of $77 \pm 22 \mathrm{~g}$ and an average $( \pm$ SE) anchor weight of $37 \pm 6 \mathrm{~g}$. Furthermore, visual observations suggested that drifting $F$. vesiculosus with anchors physically affected the benthic environment by creating 1 to $2 \mathrm{~cm}$ deep furrows in the sediment surface and acted as anchor points for other drifting material (e.g. filamentous algae) forming $>1 \mathrm{~m}^{2}$ large mats of drifting material that slowly scoured over the sediment surface in response to waves and water currents (Fig. 4g,h).

\section{Intensity of Arenicola marina sediment reworking}

Arenicola marina was a conspicuous member of the benthic fauna in the study area, and the size of feeding mounts and depressions suggested that their activity could harm Zostera marina seedlings (Fig. 4d,e). The bare sediment was inhabited by a relatively constant population of $A$. marina based on the number of faecal casts (average: $4.5 \pm 0.3 \mathrm{~m}^{-2}$ ) (Fig. 5). Furthermore, the $3 \pm 0.7 \mathrm{~mm}(\mathrm{n}=89)$ average diameter of faecal casts suggested that the population consisted mainly of large individuals (Retraubun et al. 1996). Sediment reworking intensity estimated by digital image analysis was from 17 to $22 \mathrm{~cm}^{3} \mathrm{~d}^{-1}$ per A. marina, which was equivalent to $91-114 \mathrm{~cm}^{3} \mathrm{~m}^{-2} \mathrm{~d}^{-1}$ or $1 \mathrm{~cm}$ of faeces deposited at the surface per square meter per 3 mo (Fig. 5).

\section{Sediment resuspension}

Significant sediment resuspension occurred during the entire study period despite moderate wind and wave action (wind speeds and wave amplitudes rarely exceeded $10 \mathrm{~m} \mathrm{~s}^{-1}$ and $0.2 \mathrm{~m}$, respectively). Sediment resuspension covered transect lines and identification tags with a 1 to $2 \mathrm{~cm}$ thick layer of sediment between observations, indicating high sediment mobility at the site (Fig. 4f). Resuspension measured $40 \mathrm{~cm}$ above the sediment surface as TM deposition was on average $\left( \pm\right.$ SE) $173 \pm 28 \mathrm{~g}$ dry wt $\mathrm{m}^{-2} \mathrm{~d}^{-1}$ during June, July and the second half of August (Fig. 6). During the first half of August resuspension was substantially higher $(490 \pm$ $127 \mathrm{~g}_{\text {dry }} \mathrm{wt} \mathrm{m}^{-2} \mathrm{~d}^{-1}$ ). The material retrieved from sediment traps consisted mainly of fine mineral grains, but also had a high organic content (16 to $37 \%$ LOI). When considering that the sediment at Enebærodde is organically poor, with $<0.7 \%$ LOI (Table 1 ), the high organic content of trap material probably reflected preferential resuspension of the upper diatom-rich sediment layer or deposition of seagrass or macroalgal debris.
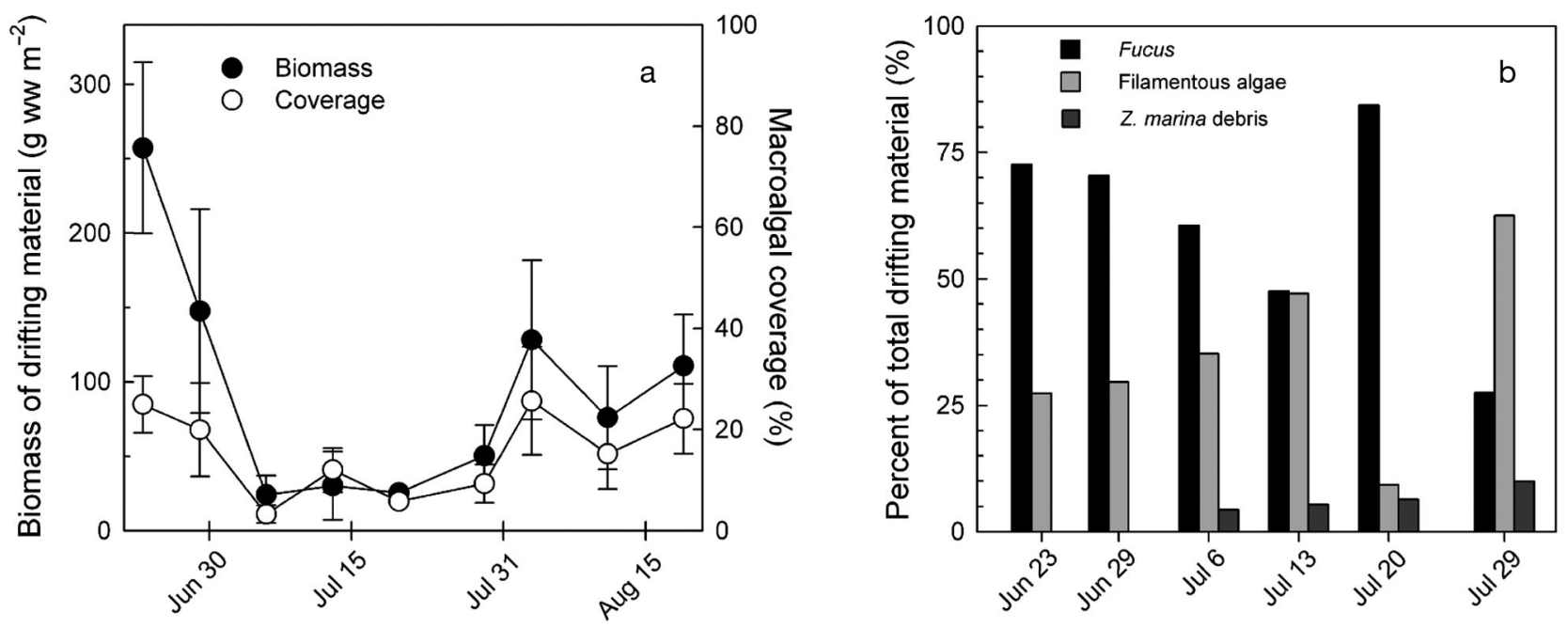

Fig. 3. (a) Total biomass of drifting material $(\bullet)$ and macroalgal coverage $(0)$ on unprotected transects. Error bars indicate SE $(\mathrm{n}=$ 3). (b) Relative contributions of debris of Fucus sp., filamentous algae and Zostera marina to total drifting material during June and July 2009 

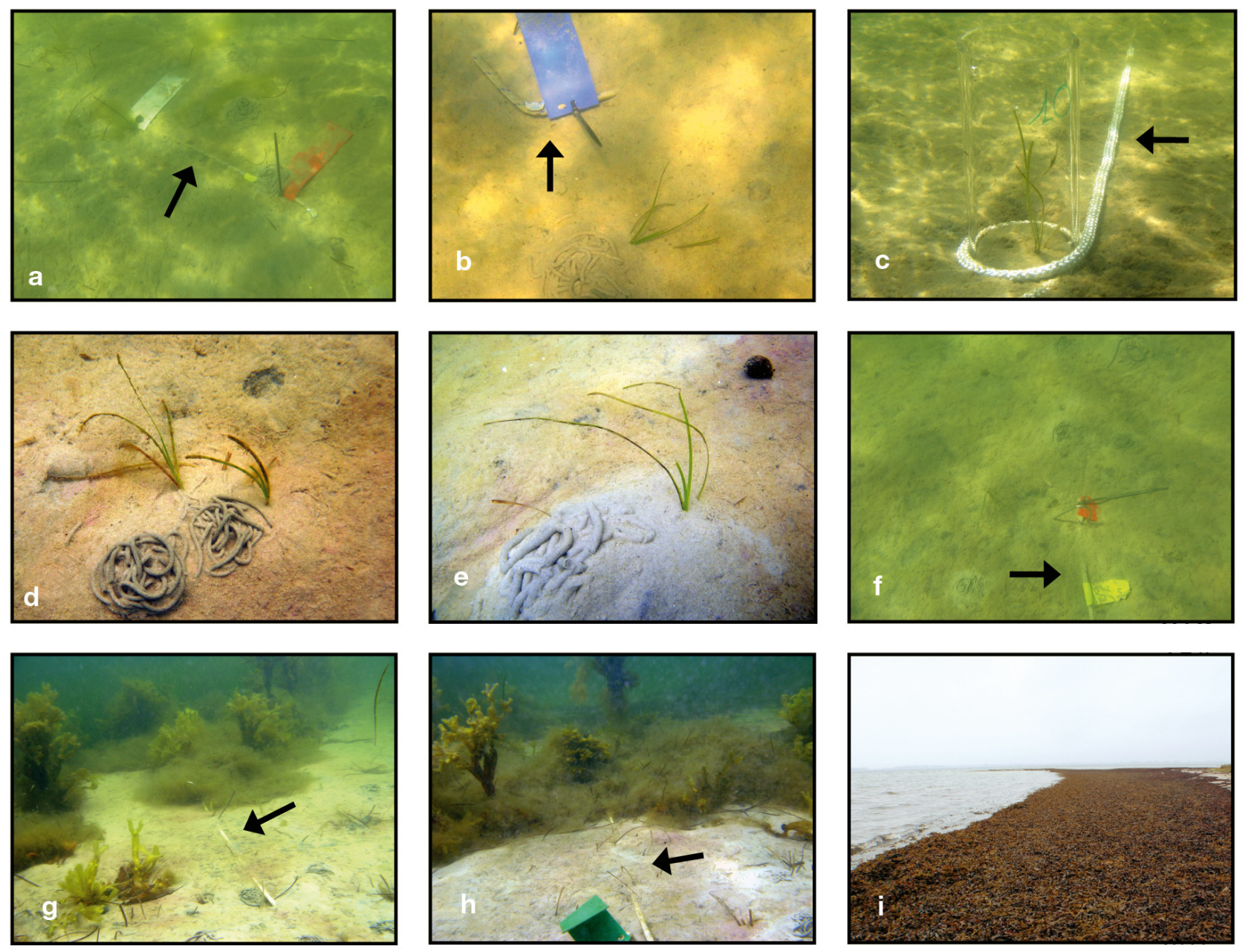

Fig. 4. (a to h) Underwater and (i) above-water photographs of the study area. (a,b) Transect cord and identification markers. (c) Zostera marina seedling protected by transparent core liner. $(d, e) Z$. marina seedlings in close proximity to Arenicola marina burrows. (f) Transect cord and identification markers partially covered by 1 to $3 \mathrm{~cm}$ of sediment. (g,h) Massive occurrence of drifting algae on transects. (i) Washed up algae (primarily Fucus sp.) that covered up to $10 \mathrm{~m}$ of the beach on several occasions. Arrows indicate position of transect cords

\section{Correlation analysis}

The temporal development of seedling density was divided into 2 phases (Fig. 2): an initial phase with consistently high loss rates (average: $3.1 \pm 0.8 \% \mathrm{~d}^{-1}$ ) from June 17 to July 13, followed by much lower loss rates from July 13 to the end of the study period (average: $0.4 \pm 0.2 \% \mathrm{~d}^{-1}$ ). This shift probably resulted from the low number of seedlings that survived after July 13 (7, 1 and 6 seedlings on Transect A, B and C, respectively). To avoid conclusions biased by this artifact, correlation analysis was only performed for the initial phase, during which $80 \%$ of the seedlings disappeared. Rates of seedling loss, macroalgal drift, sediment reworking and sediment resuspension showed a normal distribution when expressed as daily means during the period of intensive seedling loss (June 15 to July 13). Rates of seedling loss correlated significantly with total macroalgal drift ( $p=0.025)$ (Fig. 7), but not with Arenicola marina sediment reworking $(p=0.322)$ or sediment resuspension $(\mathrm{p}=0.365)$.

\section{DISCUSSION}

\section{Sediment properties}

Bare sediment characteristics were similar to those of vegetated sediment for most examined parameters (Table 1), suggesting that bare sediment was a potential substrate for Zostera marina. This is also indicated by the low rate of metabolism (e.g. $24 \mathrm{mmol} \mathrm{m}^{-2} \mathrm{~d}^{-1}$ sediment 


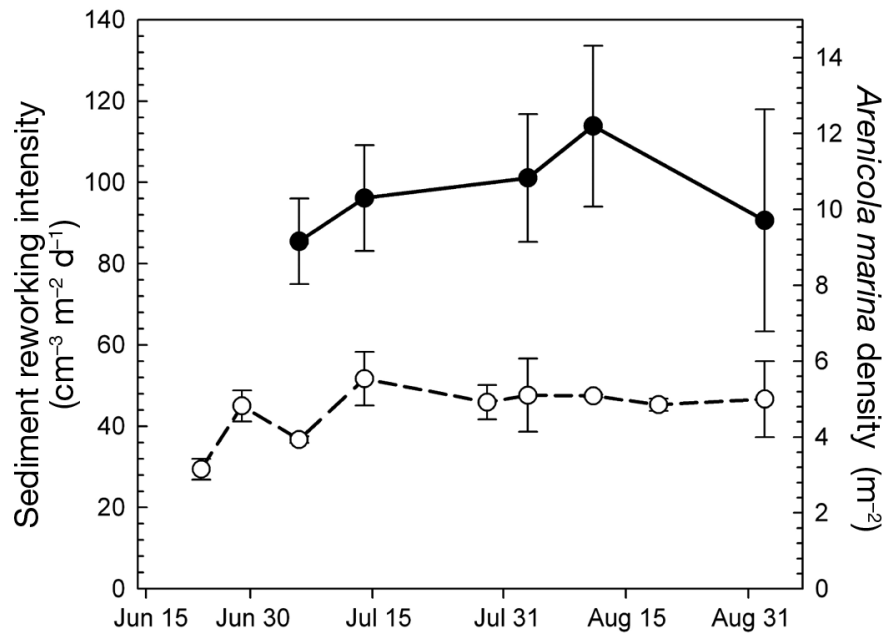

Fig. 5. Arenicola marina. Density (O) and area-specific sediment reworking intensity $(\bullet)$ determined by digital image analysis. Error bars indicate SE $(\mathrm{n}=3)$

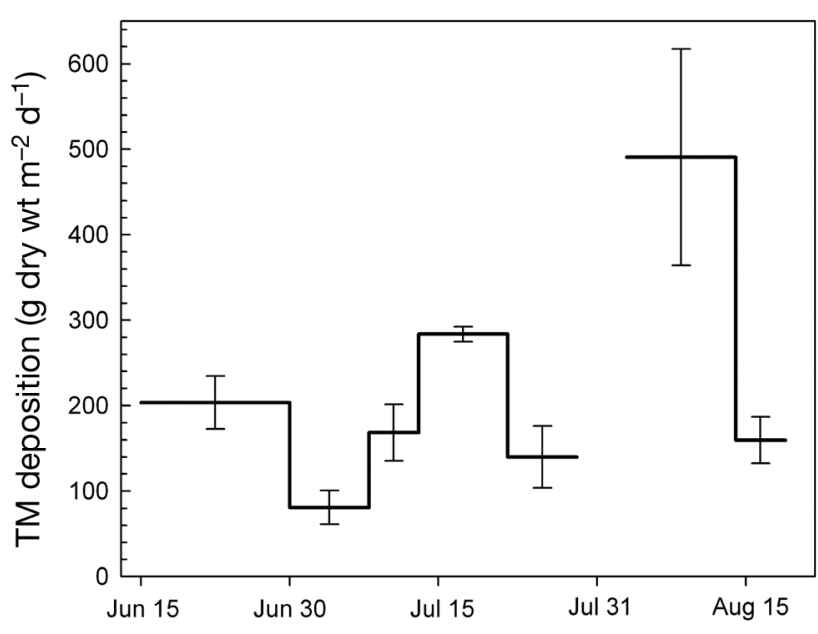

Fig. 6. Total matter (TM) deposition measured by sediment traps positioned $40 \mathrm{~cm}$ above the sediment surface. Note that TM deposition was not measured from June 29 to August 3, 2009. Error bars indicate SE $(n=4)$
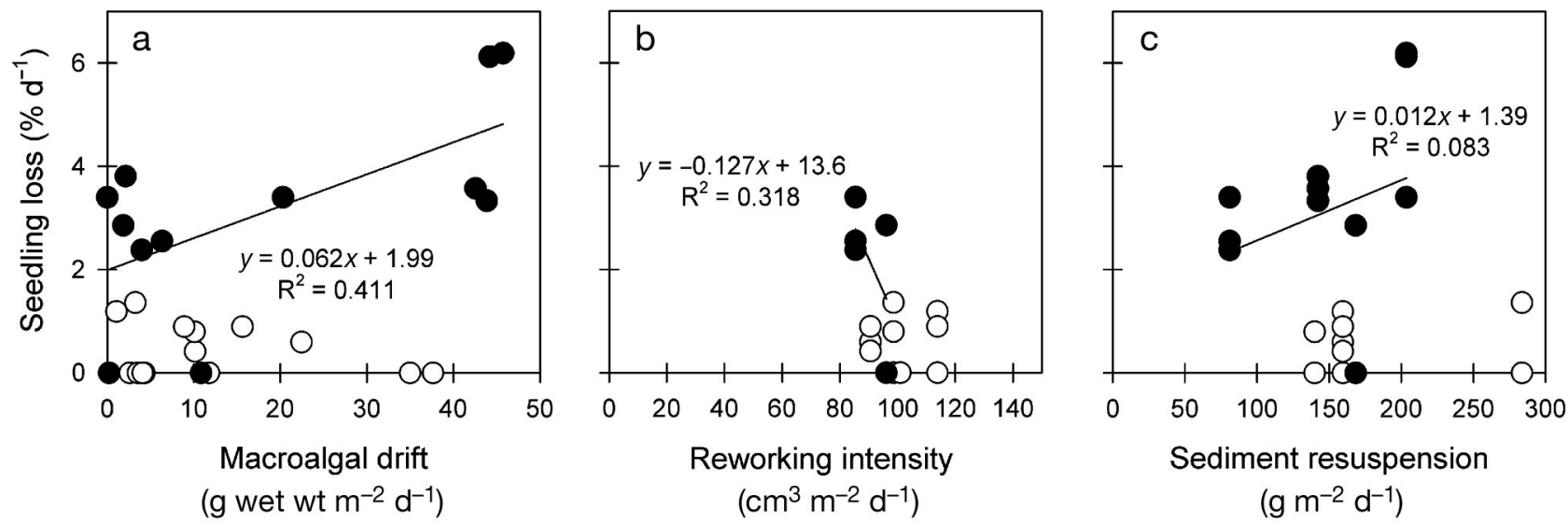

Fig. 7. Rates of Zostera marina seedling loss as a function of: (a) macroalgal drift, (b) sediment reworking and (c) sediment resuspension. Lines and equations present best linear fits. Pearson correlation analysis on data from the period of most rapid seedling loss (June 15 to July 13, 2009, indicated by $\bullet$ ) showed that rates of seedling loss correlated with macroalgal drift $(\mathrm{r}=0.641, \mathrm{n}=12$, $\mathrm{p}=0.02)$, but not with Arenicola marina reworking intensity $(\mathrm{r}=0.563, \mathrm{n}=5, \mathrm{p}=0.32)$ or sediment resuspension $(\mathrm{r}=0.286$, $\mathrm{n}=$ $12, p=0.36)$. ( $(0)$ Data that were excluded from regression lines (i.e. data generated after July 13)

$\mathrm{O}_{2}$ uptake) and the low porewater accumulation of hydrogen sulfide and $\mathrm{NH}_{4}^{+}(20$ and $200 \mu \mathrm{M}$, respectively) in this sediment (T. Valdemarsen unpubl. data). These latter values are below the limits causing toxic effects in Z. marina (e.g. Goodman et al. 1995, van Katwijk et al. 1997, Hauxwell et al. 2001, Mascaro et al. 2009).

\section{Effect of drifting macroalgae on seedling mortality}

Drift estimates of up to $260 \mathrm{~g}$ wet wt $\mathrm{m}^{-2}$ algal material between weekly observations are most likely tran- sitory net macroalgal accumulation; thus, they probably underestimate the dynamics and high amounts of drifting algae in the study area. This is supported by a few events of intense macroalgal drift in late July and the beginning of August, where the nearby beach was covered by a $>10 \mathrm{~m}$ wide and 30 to $40 \mathrm{~cm}$ deep belt of wrack (primarily Fucus) within a few days (Fig. 4i). During such events, the sediment surface must have been constantly swept by drifting macroalgae transported as bedload at low to moderate current speeds (Flindt et al. 2004, Canal-Vergés et al. 2010) and unprotected seedlings may have been severely affected by physical disturbance. The importance of Fucus sp. 
attached to anchors (comprising up to $50 \%$ of drifting matter) was surprising, since drift of Fucus sp. has mainly been related to biomass sloughing at moderate to high current speeds $\left(>30 \mathrm{~cm} \mathrm{~s}^{-1}\right)$, while entire plants attached to anchors are not considered susceptible to drift (Flindt et al. 2007). Nonetheless, Fucus sp. attached to heavy stones (>200 g) were identified among drifting individuals in the present study, suggesting that Fucus sp. is highly mobile. Drift of Fucus sp. has subsequently been verified in annular flume experiments with medium-sized algae attached to $35 \mathrm{~g}$ heavy anchors at current speeds of $>10$ to $14 \mathrm{~cm} \mathrm{~s}^{-1}$ (K. Wendelboe \& J. T. Egelund unpubl. data).

The significant positive correlation between seedling loss and macroalgal drift from June 15 to July 13 suggests that drifting macroalgae explain at least $40 \%$ of seedling mortality (Fig. 7). A similar potential effect of drifting algae on both adult Zostera marina and seedlings has previously been reported, although the mechanism remains unclear (Hauxwell et al. 2001, Boese \& Robbins 2008, Boese et al. 2009, van Katwijk et al. 2010). Most previous studies have focused on adult seagrass, and primarily identified light attenuation through macroalgal canopies (Hauxwell et al. 2001, McGlathery 2001, Lamote \& Dunton 2006) and macroalga-driven hypoxia and toxic metabolite accumulation (Hauxwell et al. 2001, Lamote \& Dunton 2006, Holmer \& Nielsen 2007, Holmer et al. 2009) as processes by which drifting macroalgae negatively impact seagrasses. These processes may also be relevant for seedlings, but our results suggest that the ballistic impact of drifting macroalgae, i.e. the physical impact of macroalgae scouring over the sediment surface leading to damaged or uprooted seedlings (CanalVergés et al. 2010), was most important in the outer part of Odense Fjord. This is based on several observations: (1) seedlings protected from physical disturbance showed much lower mortality (Fig. 2); (2) seedlings disappeared abruptly between observations, with no recovery of remains of lost seedlings (e.g. rhizomes) despite knowledge about their exact position along transects; (3) a high frequency of physically damaged seedlings was observed in the study area; and, finally, (4) the disappearance of healthy seedlings between observations did not agree with the slow and gradual deterioration over weeks to months observed for seagrass subjected to poor growth conditions (van Katwijk et al. 1997, Bintz \& Nixon 2001, Hauxwell et al. 2001, Holmer \& Nielsen 2007, Mascaro et al. 2009). The present study does not rule out the importance of macroalga-driven hypoxia and sulfide accumulation, and we may have relieved this effect by regularly cleaning transects for drifting algae. However, the oxidized sediment surface (e.g. light brown coloration indicative of oxidized $\mathrm{Fe}$ ) and lack of sulfide odor beneath non- manipulated macroalgal mats indicated an absence of hypoxia. This may be due to the highly mobile macroalgal mats as opposed to previous studies where macroalgal mats were described as stagnant (e.g. Hauxwell et al. 2001, Lamote \& Dunton 2006).

The drifting Fucus sp. probably originated in the shallow northeastern basin of the outer Odense Fjord, where Fucus sp. is the dominating benthic vegetation. Our observations indicate that Fucus sp. shows synchronized drift events triggered by strong wind after prolonged periods of calm and favorable growth conditions during summer. Such behavior would dramatically influence the entire fjord; not only is Zostera marina recolonization severely hampered in areas susceptible to reoccurring drift events, but massive amounts of nutrients are also transported as macroalgal biomass (Salomonsen et al. 1997, 1999, Flindt et al. 2004). Since macroalgal drift is a common phenomenon worldwide (e.g. Valiela et al. 1997, 2000, Hauxwell et al. 2001, 2003, Martins et al. 2001, Flindt et al. 2004, Kopecky \& Dunton 2006, Boese \& Robbins 2008), the ballistic impact of drifting macroalgae may be a widespread but not yet defined problem that affects seagrass distribution in many estuaries.

\section{Effect of sediment reworking on seedling mortality}

It is known that Arenicola marina may negatively affect Zostera noltii distribution due to burial of shoots and seedlings by reworking activities (Philippart 1994). A similar negative interaction has been suggested to explain the exclusion of $Z$. japonica and $Z$. marina by burrowing thallasinid shrimps (Dumbauld \& Wyllie-Echeverria 2003). In the present study, $A$. marina may, therefore, have affected $Z$. marina negatively. There was, however, no significant correlation between reworking intensity and loss of seedlings in the present study, which may be due to the low number of observations during the period of most rapid seedling loss (Fig. 7). Nonetheless, when considering the size of individual feeding mounts and depressions (up to $6-8 \mathrm{~cm}$ height and depth, respectively), burial by A. marina is a potential mechanism for seedling loss, especially when considering that only 2 to $4 \mathrm{~cm}$ burial depth is fatal for $Z$. marina and other seagrasses (Mills \& Fonseca 2003, Cabaco \& Santos 2007, Cabaco et al. 2008). Partially buried seedlings due to faecal casts were observed on a few occasions (Fig. 4d,e), but it remains unknown if burial was fatal to those particular seedlings. Another possible explanation for the apparent lack of impact of sediment reworking is the limited and patchy abundance of $A$. marina at the study site, where only seedlings in the vicinity of 
A. marina individuals were at risk. While this risk was relatively modest in June, when seedling density was low, higher impacts of A. marina are expected in spring when seedlings are most abundant.

\section{Effect of sediment resuspension on seedling mortality}

The high amount of sediment resuspended to $>40 \mathrm{~cm}$ above the sediment surface (on average $218 \pm$ $51 \mathrm{~g} \mathrm{~m}^{-2} \mathrm{~d}^{-1}$ ) indicated high sediment mobility at the study site (roughly $\sim 1 \mathrm{~mm} \mathrm{wk}^{-1}$, with a $2 \mathrm{~g} \mathrm{~cm}^{-3}$ sediment density). Sediment resuspension decreases upwards in the water column, and sediment transport near the sediment surface must have exceeded trap measurements considerably. This is in accordance with observations of 2 to $3 \mathrm{~cm}$ of sediment displacement every week, based on burial of transect tags and cords (Figs. 4f \& 6). The high and constant sediment resuspension is puzzling, since it occurred even under low wind and wave conditions, and may be linked to the scouring effects of drifting macroalgae that induce sediment resuspension at low current speeds (CanalVergés et al. 2010).

Several studies show a dramatic impact of hydrodynamic forcing on seagrasses (Olesen \& Sand-Jensen 1994, Fonseca \& Bell 1998, van Katwijk \& Hermus 2000, Bos \& van Katwijk 2007), which is probably due to current-driven resuspension events that lead to uprooted or buried shoots and a negative effect on growth and survival (van Katwijk \& Hermus 2000, Mills \& Fonseca 2003, Cabaco \& Santos 2007). The effect of burial and erosion on seagrasses has mainly been evaluated for massive sediment translocation induced by anthropogenic activities or extreme weather events (e.g. Cabaco et al. 2008 and references therein), while the effect of small-scale resuspension has largely been ignored. Nonetheless, frequent instances of resuspension of from 1 to $3 \mathrm{~cm}$ sediment $\mathrm{wk}^{-1}$ are common in seagrass habitats (e.g. Gacia \& Duarte 2001, Widdows et al. 2008, present study) and may be an important process for loss of shoots and seedlings. The high sediment mobility we observed ( 2 to $3 \mathrm{~cm} \mathrm{wk}^{-1}$ ) may have led to uprooted and buried seedlings (Mills \& Fonseca 2003, Cabaco \& Santos 2007). This was not supported by correlations between seedling loss and total matter deposition (Fig. 7), probably due to the low range of resuspension rates measured $40 \mathrm{~cm}$ above the sediment. We, therefore, speculate that quantification of resuspension closer to the sediment surface might have produced significant results. Nonetheless, the effect of small-scale sediment translocation on seedling mortality at low to moderate current regimes should be considered in future studies.

\section{CONCLUSIONS}

The present study shows that the entire annual cohort of Zostera marina seedlings in Odense Fjord can potentially be eliminated during short periods of intense macroalgal drift, which was emphasized by the much lower mortality of seedlings protected from macroalgal drift and other physical disturbance. Drifting macroalgae may, therefore, have wide implications for the reestablishment of $Z$. marina in the fjord, since most remaining populations are located in areas similar to the study site at Enebærodde (e.g. shallow coastal areas subjected to moderate wave and current forcing) (Fyns Amt 2006). It remains uncertain, however, whether the entire fjord is impacted, and more research is needed to investigate the spatio-temporal dynamics of macroalgal drift. Furthermore, other processes may also have impacted seedling mortality, since macroalgal drift only explained $\sim 40 \%$ of seedling loss. Burial and undermining by Arenicola marina reworking and sediment resuspension are likely processes, although no significant correlation with seedling loss effects was evident at present. Nonetheless, these processes may prove highly significant during early seedling establishment or in areas not impacted by macroalgal drift. In conclusion, based on the present study we advocate considering naturally occurring physical disturbance during future studies of seagrass patch dynamics and recruitment.

Acknowledgements. We thank Jonas T. Egelund and Kim Wendelboe for assistance during laboratory and field work. We also thank 3 anonymous reviewers for their suggestions to improve the manuscript. This research was supported by the Danish Strategic Science Foundation through a grant (09063190/DSF) for the project: 'Key parameters and processes affecting the re-establishment of eelgrass in estuaries and coastal waters.'

\section{LITERATURE CITED}

Almela ED, Marba N, Alvarez E, Santiago R, Martinez R, Duarte CM (2008) Patch dynamics of the Mediterranean seagrass Posidonia oceanica: implications for recolonisation process. Aquat Bot 89:397-403

Bell SS, Robbins BD, Jensen SL (1999) Gap dynamics in a seagrass landscape. Ecosystems 2:493-504

Bintz JC, Nixon SW (2001) Responses of eelgrass Zostera marina seedlings to reduced light. Mar Ecol Prog Ser 223: 133-141

Boese BL, Robbins BD (2008) Effects of erosion and macroalgae on intertidal eelgrass (Zostera marina) in a northeastern Pacific estuary (USA). Bot Mar 51:247-257

> Boese BL, Kaldy JE, Clinton PJ, Eldridge PM, Folger CL (2009) Recolonization of intertidal Zostera marina L. (eelgrass) following experimental shoot removal. J Exp Mar Biol Ecol 374:69-77

> Bos AR, van Katwijk MM (2007) Planting density, hydrodynamic exposure and mussel beds affect survival of 
transplanted intertidal eelgrass. Mar Ecol Prog Ser 336: 121-129

Cabaco S, Santos R (2007) Effects of burial and erosion on the seagrass Zostera noltii. J Exp Mar Biol Ecol 340:204-212

> Cabaco S, Santos R, Duarte CM (2008) The impact of sediment burial and erosion on seagrasses: a review. Estuar Coast Shelf Sci 79:354-366

Canal-Vergés P, Vendel M, Valdemarsen T, Kristensen E, Flindt MR (2010) Resuspension created by bedload transport of macroalgae: implications to ecosystem functioning. Hydrobiologia 649:69-76

- Churchill AC (1983) Field studies on seed-germination and seedling development in Zostera marina L. Aquat Bot 16: 21-29

> Cummins SP, Roberts DE, Zimmerman KD (2004) Effects of the green macroalga Enteromorpha intestinalis on macrobenthic and seagrass assemblages in a shallow coastal estuary. Mar Ecol Prog Ser 266:77-87

> Davis RC, Short FT, Burdick DM (1998) Quantifying the effects of green crab damage to eelgrass transplants. Restor Ecol 6:297-302

Dumbauld BR, Wyllie-Echeverria S (2003) The influence of burrowing thalassinid shrimps on the distribution of intertidal seagrasses in Willapa Bay, Washington, USA. Aquat Bot 77:27-42

Flindt MR, Neto J, Amos CL, Pardal MA, Bergamasco A, Pedersen CB, Andersen FØ (2004) Plant bound nutrient transport. Mass transport in estuaries and lagoons. In: Nielsen SL, Banta G, Pedersen MF (eds) Estuarine nutrient cycling: the influence of primary producers. Kluwer Academic Publishers, Dordrecht, p 93-128

> Flindt MR, Pedersen CB, Amos CL, Levy A, Bergamasco A, Friend PL (2007) Transport, sloughing and settling rates of estuarine macrophytes: mechanisms and ecological implications. Cont Shelf Res 27:1096-1103

Fonseca MS, Bell SS (1998) Influence of physical setting on seagrass landscapes near Beaufort, North Carolina, USA. Mar Ecol Prog Ser 171:109-121

> Frederiksen M, Krause-Jensen D, Holmer M, Laursen JS (2004) Long-term changes in area distribution of eelgrass (Zostera marina) in Danish coastal waters. Aquat Bot 78: $167-181$

Fyns Amt (2006) Miljøfarlige stoffer og Ålegræs i Odense Fjord. Fyns Amt, Natur- og Vandmiljøafdelingen, Odense

> Gacia E, Duarte CM (2001) Sediment retention by a Mediterranean Posidonia oceanica meadow: the balance between deposition and resuspension. Estuar Coast Shelf Sci 52: 505-514

Goodman JL, Moore KA, Dennison WC (1995) Photosynthetic responses of eelgrass (Zostera marina L) to light and sediment sulfide in a shallow barrier-island lagoon. Aquat Bot 50:37-47

> Greening H, Janicki A (2006) Toward reversal of eutrophic conditions in a subtropical estuary: water quality and seagrass response to nitrogen loading reductions in Tampa Bay, Florida, USA. Environ Manag 38:163-178

> Greve TM, Krause-Jensen D, Rasmussen MB, Christensen PB (2005) Means of rapid eelgrass (Zostera marina L.) recolonisation in former dieback areas. Aquat Bot 82:143-156

- Harrison PG (1993) Variations in demography of Zostera marina and $Z$. noltii on an intertidal gradient. Aquat Bot 45:63-77

Hauxwell J, Cebrian J, Furlong C, Valiela I (2001) Macroalgal canopies contribute to eelgrass (Zostera marina) decline in temperate estuarine ecosystems. Ecology 82:1007-1022

> Hauxwell J, Cebrian J, Valiela I (2003) Eelgrass Zostera marina loss in temperate estuaries: relationship to land- derived nitrogen loads and effect of light limitation imposed by algae. Mar Ecol Prog Ser 247:59-73

Holmer M, Nielsen RM (2007) Effects of filamentous algal mats on sulfide invasion in eelgrass (Zostera marina). J Exp Mar Biol Ecol 353:245-252

Holmer M, Marba N, Lamote M, Duarte CM (2009) Deterioration of sediment quality in seagrass meadows (Posidonia oceanica) invaded by macroalgae (Caulerpa sp.). Estuaries Coasts 32:456-466

Jarvis JC, Moore KA (2010) The role of seedlings and seed bank viability in the recovery of Chesapeake Bay, USA, Zostera marina populations following a large-scale decline. Hydrobiologia 649:55-68

Kopecky AL, Dunton KH (2006) Variability in drift macroalgal abundance in relation to biotic and abiotic factors in two seagrass dominated estuaries in the western Gulf of Mexico. Estuaries Coasts 29:617-629

Krumbein WC (1936) Application of logarithmic moments to size frequency distributions of sediments. J Sediment Petrol 6:35-47

Lamote M, Dunton KH (2006) Effects of drift macroalgae and light attenuation on chlorophyll fluorescence and sediment sulfides in the seagrass Thalassia testudinum. J Exp Mar Biol Ecol 334:174-186

> Lee KS, Park JI, Kim YK, Park SR, Kim JH (2007) Recolonization of Zostera marina following destruction caused by a red tide algal bloom: the role of new shoot recruitment from seed banks. Mar Ecol Prog Ser 342: 105-115

- Marion SR, Orth RJ (2010) Innovative techniques for largescale seagrass restoration using Zostera marina (eelgrass) seeds. Restor Ecol 18:514-526

Martins I, Pardal MA, Lillebø AI, Flindt MR, Marques JC (2001) Hydrodynamics as a major factor controlling the occurrence of green macroalgal blooms on the influence of precipitation and river management. Estuar Coast Shelf Sci 52:165-177

> Mascaro O, Valdemarsen T, Holmer M, Perez M, Romero J (2009) Experimental manipulation of sediment organic content and water column aeration reduces Zostera marina (eelgrass) growth and survival. J Exp Mar Biol Ecol 373:26-34

McGlathery KJ (2001) Macroalgal blooms contribute to the decline of seagrass in nutrient-enriched coastal waters. J Phycol 37:453-456

- Mills KE, Fonseca MS (2003) Mortality and productivity of eelgrass Zostera marina under conditions of experimental burial with two sediment types. Mar Ecol Prog Ser 255: 127-134

Olesen B (1999) Reproduction in Danish eelgrass (Zostera marina L.) stands: size-dependence and biomass partitioning. Aquat Bot 65:209-219

Olesen B, Sand-Jensen K (1994) Patch dynamics of eelgrass Zostera marina. Mar Ecol Prog Ser 106:147-156

- Olesen B, Marba N, Duarte CM, Savela RS, Fortes MD (2004) Recolonization dynamics in a mixed seagrass meadow: the role of clonal versus sexual processes. Estuaries 27: $770-780$

> Orth RJ, Luckenbach M, Moore KA (1994) Seed dispersal in a marine macrophyte: implications for colonization and restoration. Ecology 75:1927-1939

> Orth RJ, Fishman JR, Harwell MC, Marion SR (2003) Seeddensity effects on germination and initial seedling establishment in eelgrass Zostera marina in the Chesapeake Bay region. Mar Ecol Prog Ser 250:71-79

Petersen HE (1934) Wasting disease of eelgrass (Zostera marina). Nature 134:143-144 
Petersen JD, Rask N, Madsen HB, Jorgensen OT and others (2009) Odense Pilot River Basin: implementation of the EU Water Framework Directive in a shallow eutrophic estuary (Odense Fjord, Denmark) and its upstream catchment. Hydrobiologia 629:71-89

Philippart CJM (1994) Interactions between Arenicola marina and Zostera noltii on a tidal flat in the Wadden Sea. Mar Ecol Prog Ser 111:251-257

> Plus M, Deslous-Paoli JM, Dagault F (2003) Seagrass (Zostera marina L.) bed recolonisation after anoxia-induced full mortality. Aquat Bot 77:121-134

Probert RJ, Brenchley JL (1999) The effect of environmental factors on field and laboratory germination in a population of Zostera marina L. from southern England. Seed Sci Res 9:331-339

Retraubun ASW, Dawson M, Evans SM (1996) Spatial and temporal factors affecting sediment turnover by the lugworm Arenicola marina (L). J Exp Mar Biol Ecol 201: 23-35

Salomonsen J, Flindt MR, Geertz-Hansen O (1997) Significance of advective transport of Ulva lactuca for a biomass budget on a shallow water location. Ecol Model 102: 129-132

Salomonsen J, Flindt MR, Geertz-Hansen O (1999) Modelling advective transport of Ulva lactuca (L) in the sheltered bay, Møllekrogen, Roskilde Fjord, Denmark. Hydrobiologia 397:241-252

Townsend EC, Fonseca MS (1998) Bioturbation as a potential mechanism influencing spatial heterogeneity of

Editorial responsibility: Hans Heinrich Janssen, Oldendorf/Luhe, Germany
North Carolina seagrass beds. Mar Ecol Prog Ser 169: 123-132

Vahteri P, Makinen A, Salovius S, Vuorinen I (2000) Are drifting algal mats conquering the bottom of the Archipelago Sea, SW Finland? Ambio 29:338-343

Valiela I, McClelland J, Hauxwell J, Behr PJ, Hersh D, Foreman K (1997) Macroalgal blooms in shallow estuaries: controls and ecophysiological and ecosystem consequences. Limnol Oceanogr 42:1105-1118

van der Heide T, van Nes EH, Geerling GW, Smolders AJP, Bouma TJ, van Katwijk MM (2007) Positive feedbacks in seagrass ecosystems: implications for success in conservation and restoration. Ecosystems 10:1311-1322

van Katwijk MM, Hermus DCR (2000) Effects of water dynamics on Zostera marina: transplantation experiments in the intertidal Dutch Wadden Sea. Mar Ecol Prog Ser 208:107-118

> van Katwijk MM, Vergeer LHT, Schmitz GHW, Roelofs JGM (1997) Ammonium toxicity in eelgrass Zostera marina. Mar Ecol Prog Ser 157:159-173

van Katwijk MM, Bos AR, Kennis P, de Vries R (2010) Vulnerability to eutrophication of a semi-annual life history: a lesson learnt from an extinct eelgrass (Zostera marina) population. Biol Conserv 143:248-254

> Widdows J, Pope ND, Brinsley MD, Asmus H, Asmus RM (2008) Effects of seagrass beds (Zostera noltii and Z. marina) on near-bed hydrodynamics and sediment resuspension. Mar Ecol Prog Ser 358:125-136

Submitted: May 23, 2010; Accepted: September 13, 2010 Proofs received from author(s): November 4, 2010 